\title{
A cost-effectiveness analysis of varenicline for smoking cessation using data from the EAGLES trial
}

\author{
Christine L Baker' \\ Guilhem Pietri² \\ 'Pfizer Inc., New York, NY, USA; ${ }^{2}$ Data \\ Pyxis Ltd., St Albans, UK
}

This article was published in the following Dove Press journal: ClinicoEconomics and Outcomes Research

Background: The cost-effectiveness of varenicline has been demonstrated in the US health care setting using the Benefits of Smoking Cessation on Outcomes (BENESCO) model to simulate the lifetime direct costs and consequences of a hypothetical cohort of US adult smokers who make a single attempt to quit. The aim of this study was to undertake an updated cost-effectiveness analysis, using current epidemiology inputs and recently published smoking cessation data from the Evaluating Adverse Events in a Global Smoking Cessation Study (EAGLES), the largest clinical trial of smoking cessation pharmacotherapies conducted to date.

Methods: BENESCO is a Markov model simulating the effect of a single attempt to quit smoking on four smoking-related diseases: coronary heart disease, stroke, chronic obstructive lung disease, and lung cancer. Inputs were updated to include efficacy from EAGLES and newer data for the epidemiology of smoking in the US, the epidemiology and direct treatment costs of the four morbidities, and the costs of the interventions. Analyses compared varenicline, bupropion, nicotine replacement therapy (NRT) patch, and placebo with regard to the incidence of smokingrelated morbidity, the incidence of smoking-related mortality, and cost-effectiveness at a time horizon from 2 years to lifetime.

Results: The study cohort comprised of 18,394,068 US adult smokers who made a single quit attempt during the first year of the model. For varenicline, there were an estimated 319,730 fewer smoking-related morbidities at the lifetime compared with placebo. Similarly, smoking-related mortality decreased by 198,240 subjects when varenicline was compared with placebo. For the same time horizon, varenicline was more effective and less costly, ie, dominant, compared with all comparators in the cost-effectiveness analysis.

Conclusion: Based on the BENESCO model, smoking cessation with varenicline results in reduced incidence of smoking-related morbidity and mortality compared with other smoking cessation interventions and remains a cost-effective strategy in the US population.

Keywords: cost-effectiveness, smoking cessation, varenicline, BENESCO model, EAGLES trial, smoking-related morbidity, smoking-related mortality

\section{Introduction}

Smoking is associated with considerable mortality and morbidity. ${ }^{1}$ Smoking accounts for $>5$ million premature deaths worldwide each year, ${ }^{2}$ including $>480,000$ in the US alone. ${ }^{3,4}$ It also causes a wide range of chronic diseases and cancers, which place a considerable burden on health care systems. ${ }^{1}$

Strategies for smoking cessation are important for reducing the overall smoking burden $^{4}$ and have proved to be effective. ${ }^{5}$ Between 2005 and 2014, the prevalence of cigarette smoking among US adults decreased from $20.9 \%$ to $16.8 \%$. ${ }^{3}$ Smokers' interest

Correspondence: Christine L Baker Pfizer Inc., 235 E. 42nd Street, New York, NY 10017 , USA

Tel +I 2127339545

Email Christine.L.Baker@pfizer.com 
in quitting smoking is high: in 2015, 68.0\% of current US adult daily smokers reported that they wanted to stop smoking, ${ }^{6}$ and an estimated $55.4 \%$ of all smokers had attempted to quit during the past year. ${ }^{6}$

The current clinical practice guidelines recommend that a combination of medication and counseling is most effective for obtaining cessation. ${ }^{4,5,7}$ Smoking cessation medications include nicotine replacement therapy (NRT), available both over the counter and on prescription depending on formulation, and bupropion (Zyban ${ }^{\circledR}$; GlaxoSmithKline plc, London, UK) and varenicline (Champix ${ }^{\circledR}$; Pfizer, Inc., New York, NY, USA), both available by prescription only.

The Evaluating Adverse Events in a Global Smoking Cessation Study (EAGLES), the largest clinical trial of smoking cessation pharmacotherapies to date, adopted a double-blind, triple-dummy design to compare the efficacy and neuropsychiatric safety profile of varenicline, bupropion, NRT patch, and placebo in smokers with and without psychiatric disorders. ${ }^{8}$ The study, conducted at 140 centers in 16 countries between 2011 and 2015, comprised a 12-week treatment phase and a 12-week follow-up period. ${ }^{8}$ Study participants were randomized to treatment, with stratification into nonpsychiatric and psychiatric cohorts. The primary efficacy end point was continuous smoking abstinence for Weeks 9-12, and a secondary efficacy end point was continuous abstinence for Weeks 9-24. ${ }^{8}$ Study results indicated that, for these primary and secondary end points, varenicline was more effective than bupropion, NRT patch, and placebo, and bupropion and NRT patch were more effective than placebo. ${ }^{8}$

The cost-effectiveness of smoking cessation interventions has been previously shown in several studies. ${ }^{5,-12}$ Varenicline, specifically, has been shown to be cost-effective in the US health care setting using the Benefits of Smoking Cessation on Outcomes (BENESCO) model, a Markov model developed to simulate the lifetime direct costs and consequences of a single quit attempt in a hypothetical cohort of US adult smokers. ${ }^{13}$ In light of the new comparative efficacy data from the EAGLES trial and the decreasing prevalence of smoking in the US population, the objective of this study was to update the inputs of the BENESCO model to investigate long-term health and economic outcomes of smoking cessation treatment using varenicline, bupropion, NRT patch, and placebo.

\section{Methods}

\section{The BENESCO model}

The BENESCO model was initially developed to assess the cost-effectiveness of a single smoking cessation attempt in a hypothetical cohort of US adult smokers using varenicline, bupropion, NRT, or unaided cessation. ${ }^{13}$ Designed as a Markov model, the impact of a single attempt in the first year on the incidence of smoking-related mortality and morbidity is estimated in 1-year cycles running up to a lifetime, which is set at 99 years of age, after which subjects remaining in the model will die in the next cycle due to all-cause mortality. ${ }^{13}$ This requirement ensures that all patients in the model will experience mortality through the duration of the simulation. Never and former smokers are excluded from the simulation because the initial cohort focuses on current smokers attempting to quit. ${ }^{13}$

The model includes health states corresponding to chronic obstructive lung disease (COPD), lung cancer, coronary heart disease (CHD), and stroke, in order to simulate the epidemiological pattern of the most prevalent and costly of the smokingrelated conditions. ${ }^{13}$ The transition probabilities of subjects between these health states are derived from three factors: 1) smoking status, including initial quit rate and subsequent short- or long-term relapse rates; 2) morbidity status, derived from the relative risk of developing one of the four smokingrelated morbidities; and 3) risk of mortality. ${ }^{13}$ At the conclusion of each cycle, subjects stay in the same state, undergo transition to another morbidity state, or die from one of the included morbidities or another cause (all-cause mortality).

In the present study, prevalence, incidence, mortality, direct treatment costs of smoking-related conditions, and the efficacy and costs of the smoking cessation interventions have been updated based on the current literature. Smoking-related disease health utilities and risks of these diseases relative to nonsmokers were assumed to remain unchanged over time, as previously reported. ${ }^{14}$ The BENESCO model takes the perspective of the US health care system.

\section{BENESCO model updates}

Several data updates were included in this analysis to modernize our study from the initial cost-effectiveness analyses published by Howard et al. ${ }^{13}$ The efficacy estimates used in the BENESCO model were updated to reflect comparative head-to-head data arising from the EAGLES trial. ${ }^{8}$ However, these efficacy estimates required adjustments for use within the BENESCO framework for two reasons: 1) the EAGLES trial provided efficacy end points separately for the psychiatric and nonpsychiatric populations, whereas the BENESCO model does not differentiate between the two populations, and 2) the EAGLES trial measured continuous abstinence from Week 9 to Week 24, whereas the BENESCO model uses a 52-week cycle.

The first adjustment to derive the quit rates used in the model addressed the subpopulation distribution. The 
EAGLES trial comprised two cohorts stratified by psychiatric history: 4,000 subjects with and 4,000 without a history of psychiatric disorders. Subjects with a history of psychiatric disorders were defined as having at least one of the following Axis I or II diagnoses: psychotic disorders (schizophrenia and schizoaffective disorder), mood disorders (major depression and bipolar I and II disorders), anxiety disorders (panic disorder with or without agoraphobia), posttraumatic stress disorder, obsessive-compulsive disorder, social phobia, generalized anxiety disorder, and a past history of borderline personality disorder. Due to the equal sampling between the two cohorts, subjects with psychiatric history were over represented in the EAGLES trial.

Therefore, to obtain a single quit rate which represents the distribution of psychiatric comorbidities in the general population, a literature search was conducted, and a study reporting that $29.2 \%$ of the general population was diagnosed with these conditions was identified. ${ }^{15}$ For each treatment group, the Weeks 9-24 efficacy end points from the two cohorts were pooled using a weighted average to obtain a single Weeks 9-24 quit rate representative of the distribution of psychiatric disorders in the general population (Table 1). After pooling, the Weeks 9-24 continuous abstinence rates for each treatment group were again adjusted to approximate a 1-year quit rate by applying the weighted average of the ratios of the Week 52 and Week 24 quit rates for varenicline, bupropion, and placebo from an analysis by Nides et al. ${ }^{16}$ Thus, the effectiveness of a single quit attempt for each treatment ultimately used in this study was calculated based on the Weeks 9-24 end points from EAGLES, ${ }^{8}$ pooled with data about the prevalence of psychiatric disorders in the general population, ${ }^{15}$ and extended to 52 weeks using the average abstinence ratio. ${ }^{16}$ The quit rates used in this updated model are shown in Table 1.

Additional updates to the data inputs, as previously mentioned, focused on providing newer data for the epidemiology of smoking in the US population, the epidemiology and direct treatment costs of the four smoking-related conditions included in the model, and the costs of the smoking cessation interventions. The US population figures and allcause mortality rates were identified from the US Census Bureau. ${ }^{17,18}$ The demographic breakdown of smokers included in the study cohort was estimated from Centers for Disease Control and Prevention (CDC) reports (Table 2): Current Cigarette Smoking Among Adults in the US ${ }^{3}$ and Summary Health Statistics for US Adults. ${ }^{19}$ Prevalence, incidence, and mortality rates of COPD, ${ }^{20,21}$ lung cancer, ${ }^{17,22} \mathrm{CHD},{ }^{20,23}$ and stroke $^{17,18,20,23-25}$ were identified through literature searches that included reports from the American Heart Association, the $\mathrm{CDC}$, and peer-reviewed publications.

Disease management and intervention costs were updated for each smoking-related disease and were inflated as necessary to reflect 2014 US costs by applying Medical Care Consumer Price Indexes (Table 3). ${ }^{26-29}$ The treatment costs of varenicline, bupropion, and NRT patch were defined based on the average Wholesale Acquisition Cost unit price sourced from the First DataBank's FDB MedKnowledge data, as of June 1, 2014, and the recommended course for smoking cessation. ${ }^{30}$

\section{Updated model data analysis}

After updating the BENESCO inputs as described earlier, the model was run for an entry population of 18,394,068 smokers to compare varenicline, bupropion, NRT patch, and placebo with regard to the incidence of smoking-related morbidity, the incidence of smoking-related mortality, and cost-effectiveness with a time horizon from 2 years to lifetime. A default discount rate of $3 \%$ was used for costs and outcomes. The lifetime horizon was regarded as capturing all the costs and benefits resulting from smoking and smoking cessation. A probabilistic sensitivity analysis (PSA) was conducted with 1,000 iterations at the lifetime time horizon for each pair-wise comparison of smoking cessation strategies,

Table I Derived abstinence (efficacy) rates for interventions used in BENESCO

\begin{tabular}{|c|c|c|c|c|}
\hline \multirow[t]{3}{*}{ Intervention } & \multicolumn{4}{|l|}{ Abstinence rate (\%) } \\
\hline & \multicolumn{3}{|l|}{ Weeks 9-24 } & \multirow{2}{*}{$\frac{\text { Week } 52}{\text { Estimated }^{c}}$} \\
\hline & $\begin{array}{l}\text { Patients with psychiatric } \\
\text { disorders }^{\mathrm{a}}\end{array}$ & $\begin{array}{l}\text { Patients without } \\
\text { psychiatric disorders }^{a}\end{array}$ & $\begin{array}{l}\text { Pooled } \\
\text { estimated }\end{array}$ & \\
\hline Varenicline & 18.3 & 25.5 & 23.4 & 17.9 \\
\hline Bupropion & 13.7 & 18.8 & 17.3 & 13.3 \\
\hline NRT patch & 13.0 & 18.5 & 16.9 & 13.0 \\
\hline Placebo & 8.3 & 10.5 & 9.9 & 7.6 \\
\hline
\end{tabular}


Table 220 I 4 US population figures and smoking prevalences by age and sex used in the BENESCO model 1,3,9

\begin{tabular}{lllll}
\hline Sex and age band (years) & Population size & Smoking prevalence (\%) & Smokers $(\mathbf{n})$ & No. of making quit attempt \\
\hline Males & & & & \\
$\quad$ I8-34 & $37,658,932$ & 22.6 & $8,510,919$ & $3,634,162$ \\
$35-64$ & $60,671,100$ & 21.9 & $13,286,97 \mid$ & $5,673,537$ \\
$65+$ & $19,599,94 \mid$ & 10.6 & $2,077,594$ & 887,133 \\
Females & & & & \\
I8-34 & $36,444,679$ & 16.3 & $5,940,483$ & $2,536,586$ \\
$35-64$ & $62,865,553$ & 18.1 & $11,378,665$ & $4,858,690$ \\
$65+$ & $25,104,133$ & 7.5 & $1,882,810$ & 803,960 \\
Total & $242,344,338$ & & $43,077,442$ & $18,394,068$ \\
\hline
\end{tabular}

Abbreviation: BENESCO, Benefits of Smoking Cessation on Outcomes.

Table 3 Cost inputs included in the model

\begin{tabular}{ll}
\hline Category & Annual cost, 20 I4 \$US \\
\hline Direct treatment cost & \\
COPD $^{26}$ & 20,224 \\
Lung cancer $^{29}$ & 70,110 \\
CHD $^{27}$ & 10,303 \\
Stroke & 27,422 \\
Drug cost & \\
Varenicline & \\
Bupropion & \\
NRT patch & $843^{30}$ \\
Placebo & $325^{\mathrm{a}}$ \\
\hline
\end{tabular}

Notes: ${ }^{a}$ Based on an 84 -day course of treatment. ${ }^{\text {T}}$ The cost of placebo was set at zero.

Abbreviations: CHD, chronic heart disease; COPD, chronic obstructive pulmonary disease; NRT, nicotine replacement therapy.

resulting in cost-effectiveness acceptability curves and costeffectiveness planes.

\section{Results}

The updated BENESCO model showed that, as expected, the cumulative incidence of COPD, lung cancer, CHD, and stroke at the lifetime horizon varied according to treatment efficacy, with varenicline having the lowest cumulative incidence of these conditions and placebo having the highest (Table 4). For varenicline, there were an estimated 319,730 fewer smoking-related morbidities over the lifetime compared with placebo. Compared with bupropion and NRT, use of varenicline resulted in 175,998 and 166,156 fewer smoking-related morbidities over the lifetime, respectively (Table 4). A similar trend was observed at other time horizons.

Similarly, the cumulative incidence of smoking-related deaths from these conditions recorded at each time horizon was also lowest with varenicline and highest with placebo (Table 5). At a lifetime horizon, smoking-related mortality rates decreased by 198,240 patients with varenicline compared with placebo (bupropion, 109,123; NRT patch, 103,021). Compared with bupropion and NRT patch, treatment with varenicline resulted in 89,117 and 95,219 fewer deaths, respectively.

Annual treatment-related costs were higher for varenicline than for the other comparators at the time horizons of 2, 5, and 10 years (Table 6). At these time horizons, varenicline, bupropion, and NRT patch were all more expensive than placebo. At the 20-year horizon, treatment-related costs were lower for varenicline than for NRT patch. At the lifetime horizon, total costs (including costs of interventions and smoking-related conditions) were lower for varenicline than for bupropion or NRT patch, and both varenicline and bupropion had considerably lower total costs than NRT patch and placebo. At all time horizons, quality-adjusted life years (QALYs) gained was greatest for varenicline, followed by bupropion, NRT patch, and placebo (Table 6). As a result of these data, at the lifetime horizon, varenicline dominated all comparator strategies, being more effective and less costly overall, while bupropion dominated NRT patch and placebo, and NRT patch dominated placebo (Table 7).

For each pairwise treatment comparison, a PSA based on 1,000 simulations resulted in the median estimated incremental cost-effectiveness ratio (ICER) changing by $<0.1 \%$ for each additional simulation, indicating that the aggregate results were stable. From the PSAs conducted for varenicline versus each comparator at the lifetime horizon, greatest uncertainty in cost-effectiveness was observed for varenicline versus bupropion and varenicline versus NRT patch (data not shown). In all pairwise treatment comparisons, both costs and QALYs were consistently in favor of varenicline across the majority of PSA iterations. As a result, the probability of varenicline being a cost-effective strategy compared to placebo and NRT approached $100 \%$ and compared to bupropion $85 \%$ beyond the $\$ 10,000 /$ QALY threshold.

\section{Discussion}

The aim of this study was to undertake an updated costeffectiveness analysis, using current epidemiology inputs 
Table 4 Cumulative incidence of smoking-related morbidities for varenicline versus other treatments estimated using the BENESCO model

\begin{tabular}{|c|c|c|c|c|c|}
\hline \multirow[t]{2}{*}{ Morbidity } & \multicolumn{4}{|c|}{ Model year } & \multirow[t]{2}{*}{ Lifetime } \\
\hline & 2 & 5 & 10 & 20 & \\
\hline \multicolumn{6}{|l|}{ Varenicline } \\
\hline COPD & 35,048 & 104,875 & 247,302 & 628,021 & $1,696,165$ \\
\hline Lung cancer & 56,560 & 167,696 & 407,405 & $1,049,365$ & $2,861,506$ \\
\hline CHD & 63,205 & 170,952 & 378,044 & 842,332 & $1,735,185$ \\
\hline Stroke & 36,084 & 101,808 & 239,546 & 564,833 & $1,253,474$ \\
\hline Total & 190,897 & 545,331 & $1,272,296$ & $3,084,551$ & $7,546,331$ \\
\hline \multicolumn{6}{|l|}{ Bupropion } \\
\hline COPD & 35,282 & 105,838 & 253,208 & 645,606 & $|, 738| 4 \mid$, \\
\hline Lung cancer & 57,424 & 171,379 & 419,700 & I,082,096 & $2,937,579$ \\
\hline CHD & 63,817 & 173,226 & 384,200 & 854,904 & $1,751,300$ \\
\hline Stroke & 36,547 & |03,59| & 243,753 & 573,038 & $1,263,043$ \\
\hline Total & 193,070 & 554,034 & $\mathrm{I}, 300,86 \mathrm{I}$ & $3,155,643$ & $7,690,063$ \\
\hline \multicolumn{6}{|l|}{ NRT } \\
\hline COPD & 35,298 & 105,904 & 253,612 & 646,810 & I,741,015 \\
\hline Lung cancer & 57,483 & 171,632 & 420,542 & I,084,337 & $2,942,788$ \\
\hline $\mathrm{CHD}$ & 63,859 & 173,382 & 384,622 & 855,764 & $1,752,403$ \\
\hline Stroke & 36,579 & 103,713 & $244,04 I$ & 573,600 & $1,263,699$ \\
\hline Total & 193,219 & 554,630 & $\mathrm{I}, 302,817$ & $3,160,511$ & $7,699,905$ \\
\hline \multicolumn{6}{|l|}{ Placebo } \\
\hline COPD & 35,569 & 107,016 & 260,440 & 667,138 & I,789,539 \\
\hline Lung cancer & 58,482 & 175,889 & 434,755 & $1,122,174$ & $3,030,730$ \\
\hline $\mathrm{CHD}$ & 64,566 & 176,012 & 391,738 & 870,297 & $|, 77|, 03 \mid$ \\
\hline Stroke & 37,114 & 105,775 & 248,904 & 583,085 & $|, 274,76|$ \\
\hline Total & 195,732 & 564,692 & I,335,838 & $3,242,694$ & $7,866,061$ \\
\hline
\end{tabular}

Abbreviations: BENESCO, Benefits of Smoking Cessation on Outcomes; CHD, coronary heart disease; COPD, chronic obstructive pulmonary disease; NRT, nicotine replacement therapy.

Table 5 Incidence of smoking-related mortality at different time horizons

\begin{tabular}{|c|c|c|c|c|c|}
\hline \multirow[t]{3}{*}{ Intervention } & \multicolumn{5}{|c|}{ Mortality (number of patients) } \\
\hline & \multicolumn{5}{|c|}{ Time horizon, years } \\
\hline & 2 & 5 & 10 & 20 & Lifetime \\
\hline Varenicline & $|47,5| \mid$ & 359,159 & $75 I, 621$ & $\mathrm{I}, 735,578$ & $4,497,529$ \\
\hline Bupropion & 147,798 & 362,212 & 763,431 & $\mathrm{I}, 771,001$ & $4,586,646$ \\
\hline NRT patch & 147,818 & 362,421 & 764,239 & $\mathrm{I}, 773,427$ & $4,592,748$ \\
\hline Placebo & 148,150 & 365,951 & 777,891 & $\mathrm{I}, 8 \mid 4,376$ & $4,695,769$ \\
\hline
\end{tabular}

Abbreviation: NRT, nicotine replacement therapy.

Table 6 Treatment-related costs (\$US) and quality-adjusted life years gained

\begin{tabular}{|c|c|c|c|c|c|}
\hline \multirow[t]{2}{*}{ Intervention } & \multicolumn{5}{|c|}{ Time horizon, years } \\
\hline & 2 & 5 & 10 & 20 & Lifetime \\
\hline \multicolumn{6}{|l|}{ Varenicline } \\
\hline Cost (\$ millions) & 107,064 & 225,029 & 382,508 & 640,647 & $1,011,025$ \\
\hline QALYs (I000s) & 29,743 & 69,591 & $124,1 \mid 4$ & 198,134 & 269,694 \\
\hline \multicolumn{6}{|l|}{ Bupropion } \\
\hline Cost (\$ millions) & 97,608 & 215,950 & 374,630 & 636,110 & $\mathrm{I}, 0 \mathrm{I} 1,938$ \\
\hline QALYs (1000s) & 29,742 & 69,582 & 124,073 & 197,962 & 269,199 \\
\hline \multicolumn{6}{|l|}{ NRT patch } \\
\hline Cost (\$ millions) & 102,709 & 221,077 & 379,839 & 641,548 & $1,017,749$ \\
\hline QALYs (1000s) & 29,742 & 69,581 & $|24,07|$ & 197,950 & 269,165 \\
\hline \multicolumn{6}{|l|}{ Placebo } \\
\hline Cost (\$ millions) & 91,721 & 210,523 & 370,674 & 636,246 & $1,018,747$ \\
\hline QALYs (1000s) & $29,74 \mid$ & 69,571 & 124,023 & 197,750 & 268,593 \\
\hline
\end{tabular}

Abbreviations: NRT, nicotine replacement therapy; QALY, quality-adjusted life year. 
Table 7 Cost-effectiveness (lifetime horizon)

\begin{tabular}{|c|c|c|c|c|}
\hline \multirow[t]{3}{*}{ Intervention } & \multicolumn{4}{|c|}{ ICER (\$/QALY gained) } \\
\hline & \multicolumn{4}{|l|}{ Comparator } \\
\hline & Varenicline & Bupropion & NRT patch & Placebo \\
\hline Varenicline & - & Dominant & Dominant & Dominant \\
\hline Bupropion & & - & Dominant & Dominant \\
\hline NRT patch & & & - & Dominant \\
\hline
\end{tabular}

Note: Dominant: more effective and less costly than comparator.

Abbreviations: ICER, incremental cost-effectiveness ratio; NRT, nicotine replacement therapy; QALY, quality-adjusted life year.

and recently published smoking cessation data from the EAGLES trial.

The results of this present cost-effectiveness analysis indicate that smoking cessation provides good value for money. Compared with bupropion or NRT patch, varenicline, the most efficacious pharmacotherapy, appears to prevent the greatest number of cases of smoking-related disease and death while providing a long-term economic benefit. The results demonstrate that varenicline is dominant, ie, less costly and more effective, at the lifetime horizon vs bupropion, NRT, and placebo. These cost-effectiveness results are comparable with the results originally published by Howard et $\mathrm{a}^{13} 10$ years earlier.

The population estimates reflecting the proportion of US adult smokers who make an attempt to quit reflect the trend toward a decreased smoking prevalence in the US in the past few years, as well as the changed prevalence of smokingrelated disease. ${ }^{3}$ Based on the lifetime results, the number needed to treat (NNT) to prevent one smoking-related death was estimated to be 93 for varenicline, 169 for bupropion, and 179 for NRT patch. Similarly, the NNT to prevent one case of smoking-related morbidity was estimated to be 58 for varenicline, 105 for bupropion, and 111 for NRT patch.

A key strength of this study is that it is the first to present cost-effectiveness analyses of all three smoking cessation treatments using data obtained from EAGLES, the largest head-to-head study of varenicline, bupropion, and NRT patch. Additionally, the data inputs were updated to reflect the changing landscape of smoker demographics and epidemiology of smoking-related disease over the past decade. Finally, the study population was more representative of the general population with the inclusion of patients having a psychiatric history, in comparison with the study population from previous clinical trials in which these patients were excluded by design.

A limitation of this study is that pooling was required to consolidate the efficacy values of the two subpopulations for each intervention. Unfortunately, there was no identified published study of the distribution of psychiatric diagnoses in the current smoker population, and thus, prevalence of psychiatric diagnoses in the general population was used. While the magnitude of the prevalence of psychiatric diagnosis in the general population may be debated, a recently published meta-analysis was used. ${ }^{15}$ Furthermore, the model also had to project efficacy to 52 weeks from the 24-week data that were available. Since relapse after quitting is essentially independent of the method of quitting, a ratio of the 24- and 52-week data weighted from the Nides et $\mathrm{al}^{16}$ study provided a reasonable 6 -month relapse rate. Additionally, the study design utilized in the Nides et a $1^{16}$ study was comparable with the EAGLES study design and included three of the four EAGLES treatment arms (varenicline, bupropion, and placebo).

Additional limitations inherent in the methodology included the absence of indirect costs, such as lost productivity, the effects of each pharmacotherapy on the costs of other treatments, and the potential increased costs of health care for former smokers over their assumed longer life span versus smokers. Furthermore, the model structure captures only four disease states and allows for only one morbidity at any given cycle, which is an over simplification of the true clinical impact of smoking. However, this assumption is conservative, and likely the economic results are therefore an underestimate of the true impact of smoking cessation. An area of future research would be in further refining the efficacy of smoking cessation and associated cost implications by age groups to understand the implications of smoking cessation across different age ranges and in conducting a study on the impact of retreatment with varenicline following an unsuccessful first attempt in the US setting.

\section{Conclusion}

This study, an update to the original varenicline cost-effectiveness study published by Howard et al, ${ }^{31}$ demonstrated consistency in the findings that a single quit attempt with varenicline is less costly and more effective than other smoking cessation pharmacotherapies at the lifetime despite changing smoker demographics, epidemiology of smoking-related disease, and varying costs over the past decade. 


\section{Acknowledgments}

The design and conduct of the study were supported and funded by Pfizer Inc., New York, NY, USA. Development, processing charges, and open access fee for this publication were funded by Pfizer Inc. Margarida Augusto, Anne Jakel, and Nicholas Rusbridge of PAREXEL Access Consulting, PAREXEL International, provided modeling and/or editorial support, which were funded by Pfizer Inc. All the authors met the International Committee of Medical Journal Editors criteria for authorship, took responsibility for the integrity of the work, and approved the published version.

\section{Disclosure}

Christine L Baker is an employee and stockholder of Pfizer Inc. Guilhem Pietri was an employee of PAREXEL Access Consulting, PAREXEL International, during the study; PAREXEL was a paid contractor to Pfizer in connection with the adaptation of the model and the development of this manuscript. The authors report no other conflicts of interest in this work.

\section{References}

1. World Health Organization. Economics of Tobacco Toolkit: Assessment of the Economic Costs of Smoking; 2011. Available from: http:// apps.who.int/iris/bitstream/10665/44596/1/9789241501576_eng.pdf. Accessed August 29, 2017.

2. World Health Organization [webpage on the Internet]. Tobacco Fact sheet, No. 339; 2017. Available from: http://www.who.int/mediacentre/ factsheets/fs339/en/. Accessed August 29, 2017.

3. Jamal A, Agaku IT, O'Connor E, King BA, Kenemer JB, Neff L. Current cigarette smoking among adults - United States, 2005-2013. MMWR Morb Mortal Wkly Rep. 2014;63(47):1108-1112.

4. U.S. Department of Health and Human Services. The Health Consequences of Smoking - 50 Years of Progress. A Report of the Surgeon General. Atlanta: U.S. Department of Health and Human Services, Centers for Disease Control and Prevention, National Center for Chronic Disease Prevention and Health Promotion, Office on Smoking and Health; 2014.

5. Fiore MC, Jaén CR, Baker TB, et al. Treating Tobacco Use and Dependence: 2008 Update. Clinical Practice Guideline. Rockville, MD: U.S. Department of Health and Human Services. Public Health Service; 2008.

6. Babb S, Malarcher A, Schauer G, Asman K, Jamal A. Quitting smoking among adults - United States, 2000-2015. MMWR Morb Mortal Wkly Rep. 2017;65(52):1457-1464.

7. National Institute for Health and Care Excellence [webpage on the Internet]. Smoking: Supporting People to Stop, Quality Standard [QS43]; Quality Statement 3; 2013. Available from: https://www.nice. org.uk/guidance/qs43. Accessed August 29, 2017.

8. Anthenelli RM, Benowitz NL, West R, et al. Neuropsychiatric safety and efficacy of varenicline, bupropion, and nicotine patch in smokers with and without psychiatric disorders (EAGLES): a double-blind, randomised, placebo-controlled clinical trial. Lancet. 2016;387(10037):2507-2520.

9. Cahill K, Stevens S, Perera R, Lancaster T. Pharmacological interventions for smoking cessation: an overview and network meta-analysis. Cochrane Database Syst Rev. 2013;(5):CD009329.

10. Hughes JR, Solomon LJ, Naud S, Fingar JR, Helzer JE, Callas PW. Natural history of attempts to stop smoking. Nicotine Tob Res. 2014;16(9):1190-1198.
11. Ruger JP, Lazar CM. Economic evaluation of pharmaco- and behavioral therapies for smoking cessation: a critical and systematic review of empirical research. Annu Rev Public Health. 2012;33:279-305.

12. Woolacott NF, Jones L, Forbes CA, et al. The clinical effectiveness and cost-effectiveness of bupropion and nicotine replacement therapy for smoking cessation: a systematic review and economic evaluation. Health Technol Assess. 2002;6(16):1-245.

13. Howard P, Knight C, Boler A, Baker C. Cost-utility analysis of varenicline versus existing smoking cessation strategies using the BENESCO Simulation model: application to a population of US adult smokers. Pharmacoeconomics. 2008;26(6):497-511.

14. Thun MJ, Apicella LF, Henley SJ. Smoking vs other risk factors as the cause of smoking-attributable deaths: confounding in the courtroom. JAMA. 2000;284(6):706-712.

15. Steel Z, Marnane C, Iranpour C, et al. The global prevalence of common mental disorders: a systematic review and meta-analysis 1980-2013. Int J Epidemiol. 2014;43(2):476-493.

16. Nides M, Glover ED, Reus VI, et al. Varenicline versus bupropion SR or placebo for smoking cessation: a pooled analysis. Am J Health Behav. 2008;32(6):664-675.

17. Murphy SL, Xu J, Kochanek KD. Deaths: final data for 2010. Natl Vital Stat Rep. 2013;61(4):1-117.

18. US Census Bureau PD. Annual Estimates of the Resident Population for Selected Age Groups by Sex for the United States, States, Counties, and Puerto Rico Commonwealth and Municipios: April 1, 2010 to July 1, 2014; 2014. Available from: https://factfinder.census.gov/faces/ tableservices/jsf/pages/productview.xhtml?src=bkmk. Accessed August $29,2017$.

19. Schiller JS, Lucas JW, Peregoy JA. Summary health statistics for U.S. Adults: national health interview survey, 2011. Vital Health Stat 10. 2012;(256):1-218.

20. Blackwell DL, Lucas JW, Clarke TC. Summary health statistics for U.S. adults: national health interview survey, 2012. Vital Health Stat 10. 2014;(260):1-161.

21. Kochanek KD, Murphy SL, Xu J. National Vital Statistics Reports. Deaths: Final Data for 2011; 2015. Available from: https://www. cdc.gov/nchs/data/nvsr/nvsr63/nvsr63_03.pdf. Accessed August 29, 2017.

22. National Cancer Institute [webpage on the Internet]. SEER Cancer Statistics Review 1975-2011; 2011. Available from: http://seer.cancer. gov/csr/1975_2011/browse_csr.php?sectionSEL=15\&pageSEL=s ect_15_table.27.html. Accessed August 29, 2017.

23. Go AS, Mozaffarian D, Roger VL, et al. Heart disease and stroke statistics - 2014 update: a report from the American Heart Association. Circulation. 2014;129(3):e28-e292.

24. Kissela BM, Khoury JC, Alwell K, et al. Age at stroke: temporal trends in stroke incidence in a large, biracial population. Neurology. 2012;79(17):1781-1787.

25. Kleindorfer DO, Khoury J, Moomaw CJ, et al. Stroke incidence is decreasing in whites but not in blacks: a population-based estimate of temporal trends in stroke incidence from the Greater Cincinnati/ Northern Kentucky Stroke Study. Stroke. 2010;41(7):1326-1331.

26. Blanchette CM, Gross NJ, Altman P. Rising costs of COPD and the potential for maintenance therapy to slow the trend. Am Health Drug Benefits. 2014;7(2):98-106.

27. Folse HJ, Goswami D, Rengarajan B, Budoff M, Kahn R. Clinical- and cost-effectiveness of LDL particle-guided statin therapy: a simulation study. Atherosclerosis. 2014;236(1):154-161.

28. Lee WC, Christensen MC, Joshi AV, Pashos CL. Long-term cost of stroke subtypes among Medicare beneficiaries. Cerebrovasc Dis. 2007;23(1):57-65.

29. Mariotto AB, Yabroff KR, Shao Y, Feuer EJ, Brown ML. Projections of the cost of cancer care in the United States: 2010-2020. J Natl Cancer Inst. 2011;103(2):117-128.

30. First Databank [webpage on the Internet]. FDB MedKnowledge ${ }^{\mathrm{TM}}$; 2014. Available from: http://www.fdbhealth.com/solutions/fdb-medknowledge/. Accessed June 1, 2014. 


\section{Publish your work in this journal}

ClinicoEconomics and Outcomes Research is an international, peerreviewed open-access journal focusing on health technology assessment, pharmacoeconomics and outcomes research in the areas of diagnosis, medical devices, and clinical, surgical and pharmacological intervention. The economic impact of health policy and health systems organization also constitute important areas of coverage. The manuscript management system is completely online and includes a very quick and fair peer-review system, which is all easy to use. Visit http://www.dovepress.com/testimonials.php to read real quotes from published authors.

Submit your manuscript here: https://www.dovepress.com/clinicoeconomics-and-outcomes-research-journal 